\title{
The FGFR1 inhibitor PD173074 induces mesenchymal-epithelial transition through the transcription factor AP-1
}

\author{
P T Nguyen ${ }^{*}, 1$, T Tsunematsu ${ }^{1}$, S Yanagisawa ${ }^{1}$, Y Kudo ${ }^{2}$, M Miyauchi ${ }^{1}$, N Kamata ${ }^{3}$ and T Takata ${ }^{*}, 1$ \\ ${ }^{1}$ Department of Oral and Maxillofacial Pathobiology, Division of Frontier Medical Science, Graduate School of Biomedical \\ and Health Sciences, Hiroshima University, 1-2-3 Kasumi, Minami-ku, Hiroshima 734-8553, Japan; ${ }^{2}$ Oral Molecular \\ Pathology, Tokushima University, Tokushima, Japan and ${ }^{3}$ Department of Oral and Maxillofacial Surgery, Division of \\ Cervico-Gnathostomatology, Graduate School of Biomedical and Health Sciences, Hiroshima University, Hiroshima, Japan
}

Background: Epithelial-mesenchymal transition (EMT) is a crucial process in cancer progression that provides cancer cells with the ability to escape from the primary focus, invade stromal tissues and migrate to distant regions. Cell lines that lack E-cadherin show increased tumorigenesis and metastasis, and the expression levels of E-cadherin and Snail correlate inversely with the prognosis of patients suffering from breast cancer or oral squamous cell carcinoma (OSCC). Moreover, recent studies have shown that most EMT cases are regulated by soluble growth factors or cytokines. Among these factors, fibroblast growth factors (FGFs) execute diverse functions by binding to and activating members of the FGF receptor (FGFR) family, including FGFR1-4. Fibroblast growth factor receptor 1 is an oncoprotein that is involved in tumorigenesis, and PD173074 is known to be a selective inhibitor of FGFR1. However, the roles of FGFR1 and FGFR1 inhibitors have not yet been examined in detail.

Methods: Here, we investigated the expression of FGFR1 in head and neck squamous cell carcinoma (HNSCC) and the role of the FGFR1 inhibitor PD173074 in carcinogenesis and the EMT process.

Results: Fibroblast growth factor receptor 1 was highly expressed in 54\% of HNSCC cases and was significantly correlated with malignant behaviours. Nuclear FGFR1 expression was also observed and correlated well with histological differentiation, the pattern of invasion and abundant nuclear polymorphism. Fibroblast growth factor receptor 1 was also overexpressed in EMT cell lines compared with non-EMT cell lines. Furthermore, treatment of HOC313 cells with PD173074 suppressed cellular proliferation and invasion and reduced ERK1/2 and p38 activation. These cells also demonstrated morphological changes, transforming from spindle- to cobble stone-like in shape. In addition, the expression levels of certain matrix metalloproteinases (MMPs), whose genes contain activator protein-1 (AP-1) promoter sites, as well as Snail1 and Snail2 were reduced following PD173074 treatment.

Conclusion: Taken together, these data suggest that PD173074 inhibits the MAPK pathway, which regulates the activity of AP-1 and induces MET. Furthermore, this induction of MET likely suppresses cancer cell growth and invasion.

Head and neck squamous cell carcinoma (HNSCC) is one of the most common types of cancer in humans, with an annual incidence of more than 500000 cases worldwide (Mao et al, 2004). Metastasis not only causes the most cancer deaths but is also the most poorly understood component of cancer pathogenesis
(Chaffer and Weinberg, 2011). To acquire motility and invasiveness, carcinoma cells must change many of their epithelial phenotypes to mesenchymal phenotypes, and this process is referred to as the epithelial-mesenchymal transition (EMT). Moreover, recent studies have shown that most EMT processes are

*Correspondence: Dr PT Nguyen; E-mail: ntpthao@hiroshima-u.ac.jp or Professor T Takata; E-mail: ttakata@hiroshima-u.ac.jp

Received 28 February 2013; revised 14 August 2013; accepted 16 August 2013;

published online 17 September 2013

(c) 2013 Cancer Research UK. All rights reserved 0007-0920/13

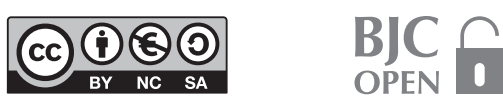


regulated by extracellular matrix (ECM) components and soluble growth factors or cytokines. Among these factors, fibroblast growth factors (FGFs) execute diverse functions by binding to and activating members of the FGF receptor family, including FGFR1-4.

Fibroblast growth factor receptor 1 (FGFR1) is a growth factor receptor tyrosine kinase, and these kinases are known regulators of various cellular processes, including proliferation, migration, survival and angiogenesis (Dailey et al, 2005). Aberrant expression or irregular activation of these FGFRs is involved in the progression of mammary tumorigenesis (Grose et al, 2007), and mutation of FGFRs is the most common genetic alteration in tumours and is strongly associated with low tumour grade and stage. Furthermore, FGFR protein expression is strongly related to mutation status (Lamont et al, 2011); specifically, several recurrent high-level gene amplifications have been identified in breast cancer. Among these genes, FGFR1 was one of the first genes shown to be amplified in $10 \%$ of cancers, including breast cancer. In addition, the amplication of FGFR1 is associated with early relapse and poor survival (Turner et al, 2010). Therefore, FGFR1 signalling may provide a valuable target for controlling tumour development.

PD173074, a previously described ATP pocket inhibitor, has reportedly shown both high affinity and selectivity for the FGFR family (Mohammadi et al, 1998). However, the roles of FGFR1 and of FGFR1 inhibitors in HNSCC have not yet been examined in detail. Here, we investigated the expression of FGFR1 in HNSCC and the roles of FGFR1 inhibitors in carcinogenesis and the EMT process.

\section{MATERIALS AND METHODS}

Clinical data and tissue samples. One hundred paraffinembedded HNSCC samples were retrieved from the pathological files of the Cancer Hospital in Ho Chi Minh City, Vietnam and Hiroshima University Hospital, Japan, following approval by the ethical committees of these institutions. The clinical details and lymph node metastasis status were gathered from the surgical records of patients. Only specimens without radiochemotherapy were selected to avoid possible influences of the treatment modality. We used the histological grading system proposed by Anneroth et al (1987) to evaluate the histopathological patterns of HNSCC samples (Table 1).

Immunohistochemistry. Unstained $4.5-\mu \mathrm{m}$ sections were cut from each paraffin block, deparaffinised and rehydrated using routine techniques. Endogenous peroxidase activity was blocked with $0.3 \% \mathrm{H}_{2} \mathrm{O}_{2}$ in methanol for 30 min before antigen retrieval by microwave treatment in citrate phosphate buffer for $20 \mathrm{~min}$. The sections were then incubated with a protein block in serum-free solution for $10 \mathrm{~min}$. The sections were incubated overnight at $4{ }^{\circ} \mathrm{C}$ with an FGFR1 monoclonal antibody (Abcam, Cambridge, MA, USA) diluted in PBS $(1: 100)$. After washing three times with PBS, the sections were incubated with appropriate peroxidase-labelled secondary antibodies for $1 \mathrm{~h}$ at room temperature. The sections were then labelled by diaminobenzidine and counterstained with Mayer's haematoxylin, dehydrated and mounted.

Immunostaining was evaluated based on the proportion of stained cancer cells and the location of the staining. Fibroblast growth factor receptor 1 expression was scored on a semiquantitative scale by evaluating the percentage of stained cells within representative areas of each tumour. For superficial carcinomas, the stained sections were observed throughout the lesion. For advanced large tumours, at least 10 fields including superficial, central and deep invasive areas were observed, and the number of stained cells and staining intensity were evaluated. In each field, we counted at least 300 cells using an eyepiece graticule to prevent recounting. The samples were then divided into two groups: those with negative ( $<50 \%$ of the cancer cells were stained) and positive staining (over $50 \%$ of the cancer cells were stained).

Statistical analysis. Correlations between the expression of FGFR1 and the clinicopathological features of HNSCC were examined using a $\chi^{2}$ test. Statistical analyses were performed using

\begin{tabular}{|c|c|c|c|c|}
\hline \multirow[b]{2}{*}{$\begin{array}{l}\text { Morphological } \\
\text { parameter }\end{array}$} & \multicolumn{4}{|c|}{ Points } \\
\hline & 1 & 2 & 3 & 4 \\
\hline \multicolumn{5}{|c|}{ Histological grading of malignancy among the tumour cell population } \\
\hline Degree of keratinisation & $\begin{array}{l}\text { Highly keratinised } \\
\text { (>50\% of the cells) }\end{array}$ & $\begin{array}{l}\text { Moderately keratinised } \\
\text { (20-50\% of the cells) }\end{array}$ & $\begin{array}{l}\text { Minimally keratinised } \\
\text { (5-20\% of the cells) }\end{array}$ & No keratinisation $(0-5 \%$ of cells) \\
\hline Nuclear polymorphism & $\begin{array}{l}\text { Little nuclear polymorphism } \\
\text { (>75\% mature cells) }\end{array}$ & $\begin{array}{l}\text { Moderately abundant nuclear } \\
\text { polymorphism (50-75\% } \\
\text { mature cells) }\end{array}$ & $\begin{array}{l}\text { Abundant nuclear } \\
\text { polymorphism } \\
\text { (25-50\% mature cells) }\end{array}$ & $\begin{array}{l}\text { Extreme nuclear polymorphism } \\
(0-25 \% \text { mature cells) }\end{array}$ \\
\hline Number of mitoses/HPF & $0-1$ & $2-3$ & $4-5$ & $>5$ \\
\hline \multicolumn{5}{|c|}{ Histological grading of malignancy for the tumour-host relationship } \\
\hline Pattern of invasion & $\begin{array}{l}\text { Pushing, well-delineated } \\
\text { infiltrating borders }\end{array}$ & $\begin{array}{l}\text { Infiltrating, solid cords, bands } \\
\text { and/or strands }\end{array}$ & $\begin{array}{l}\text { Small groups or cords of } \\
\text { infiltrating cells }(n>15)\end{array}$ & $\begin{array}{l}\text { Marked and widespread cellular } \\
\text { dissemination in small groups of } \\
\text { cells }(n<15) \text { and/or single cells }\end{array}$ \\
\hline $\begin{array}{l}\text { Stage of invasion } \\
\text { (depth) }\end{array}$ & $\begin{array}{l}\text { Carcinoma in situ and/or } \\
\text { questionable invasion }\end{array}$ & $\begin{array}{l}\text { Distinct invasion, but } \\
\text { involving the lamina propria } \\
\text { only }\end{array}$ & $\begin{array}{l}\text { Invasion below the lamina } \\
\text { propria adjacent to } \\
\text { muscles, salivary gland } \\
\text { tissues and periosteum }\end{array}$ & $\begin{array}{l}\text { Extensive and deep invasion } \\
\text { replacing most of the stromal } \\
\text { tissue and infiltrating the jaw bone }\end{array}$ \\
\hline
\end{tabular}


SPSS 21.0 (IBM, Armonk, NY, USA), and statistical significance was defined as $P<0.05$.

Chemical compounds and biological reagents. A selective inhibitor of FGFR1, PD173074, was provided by Sigma-Aldrich (Dorset, UK) and dissolved in dimethyl sulphoxide at a concentration of $1 \mu \mathrm{M}$. The stock solution was stored at $-20^{\circ} \mathrm{C}$ before use. Basic fibroblast growth factor (bFGF) was purchased from R\&D systems (Minneapolis, MN, USA).

c-Jun small interfering RNA (siRNA) (5'-CCUCAGCAACUUCA ACCC $-3^{\prime}$ ) was transfected into HOC313 cells using Oligofectamine as per the manufacturer's instructions (Invitrogen, Tokyo, Japan).

The following antibodies were used for western blotting and immunohistochemical staining: anti-FGFR1 (Abcam), anti-Ecadherin (BD Transduction Laboratories, Franklin Lakes, NJ, USA), anti-Snail1 (Santa Cruz Biotechnology, Santa Cruz, CA, USA), anti$\alpha$-tubulin (Sigma-Aldrich, St Louis, MO, USA), anti-phospho-ERK1/2, anti-ERK1/2 (Santa Cruz Biotechnology), anti-phospho-p38, anti-p38, anti-phospho-Akt, anti-Akt, anti-phospho-GSK3 $\beta$, anti-GSK3 $\alpha, \beta$, anti-phospho-c-Jun (Cell Signaling Technology, Danvers, MA, USA) and anti- $\beta$-actin (Sigma-Aldrich, Dorset, UK).

Reverse transcription-polymerase chain reaction. Total RNA was isolated and purified from fresh-frozen HNSCC tissues and cells using the RNeasy Mini Kit (Qiagen, Hilden, Germany). The isolated nucleic acids were quantified, and their purity was determined using standard spectrophotometric methods. cDNA was synthesised from $1 \mu \mathrm{g}$ total RNA using the ReverTra Dash system (Toyobo Biochemicals, Tokyo, Japan). The primer sequences were defined as follows: human $\mathrm{N}$-cadherin, 5'-GACAATGCCCCTCAAGTGTT-3' (forward) 5'-CCATTAAG CCGAGTGATGGT-3' $3^{\prime}$ (reverse); human E-cadherin, $5^{\prime}$-TGCCCA GAAAATGAAAAAGG-3' (forward) $5^{\prime}$-GGATGACAGCGTGAG AGA-3' (reverse); human $\alpha$-smooth muscle actin ( $\alpha$-SMA), $5^{\prime}$-CCGGGAGAAAATGACTCAAA-3' (forward) $5^{\prime}$-GAAGGAA TAGCCACGCTCAG-3' (reverse); human cytokeratin19, $5^{\prime}$-TTT GAGACGGAACAGGCTCT-3' (forward) 5' -AATCCACCTCCA CACTGACC-3' (reverse); human fibronectin, 5'-TCCACAAGCG TCATGAAGAG-3' (forward) 5'-ATACCACACCAGGCTTCAG G-3' (reverse); human glyceraldehyde dehydrogenase (GAPDH), 5'-ACAGTCAGCCGCATCTTCTT-3' (forward) 5' -TTGATTTT GGAGGGATCTCG-3' (reverse); human MMP1, 5'-ATGCTGAA ACCCTGAAGGTG-3' (forward) 5' -CTGCTTGACCCTCAGAGA CC-3' (reverse); human MMP3, 5'-GCAGTTTGCTCAGCC TATCC-3' (forward) 5'-GAGTGTCGGAGTCCAGCTTC-3' (reverse); human MMP10, 5'-GGCTCTTTCACTCAGCCAAC-3' (forward) 5'-TCCCGAAGGAACAGATTTTG-3' (reverse); human MMP11, $5^{\prime}$-TAGGTGCCTGCATCTGTCTG-3' (forward) $5^{\prime}$-TGGCTTTG GAGGATAGCAGT-3' (reverse); human MMP12, 5' -ACACATTT CGCCTCTCTGCT-3' (forward) $5^{\prime}$-CCTTCAGCCAGAAGAACC TG-3' (reverse); human MMP13, 5'-TTGAGCTGGACTCATTG TCG-3' (forward) 5'-GGAGCCTCTCAGTCATGGAG-3' (reverse); human Snail1, 5'-TTTACCTTCCAGCAGCCCTA-3' (forward) $5^{\prime}$-CAGTGGGGACAGGAGAAGG-3' (reverse); human Snail2, $5^{\prime}$-CTTTTTCTTGCCCTCACTGC-3' (forward) $5^{\prime}$-GCTTCGGA GTGAAGAAATGC-3' (reverse); human Twist, 5'-GTCCGCAGT CTTACGAGGAG-3' (forward) 5'-CCAGCTTGAGGGTCTGAAT C-3' (reverse); human Vimentin, 5'-GAGAACTTTGCCGTTGAA GC-3' (forward) 5' 5 $^{\prime}$ TCCAGCAGCTTCCTGTAGGT-3' (reverse); human ZEB1, 5' -TGCACTGAGTGTGGAAAAGC-3' (forward) $5^{\prime}$-TGGTGATGCTGAAAGAGACG-3' (reverse); human ZEB2, 5'-TGCCAAGAGAGGAAGAGGAA-3' (forward) 5'-GTGTCA CTGCGCTGAAGGTA-3' (reverse).

Aliquots of total cDNA were amplified with $1.25 \mathrm{U}$ of rTaq-DNA polymerase (Qiagen), and amplifications were performed in a PC701 thermal cycler (Astec, Fukuoka, Japan) for 30 cycles after an initial $30 \mathrm{~s}$ denaturation at $94^{\circ} \mathrm{C}$, consisting of annealing for $30 \mathrm{~s}$ at $60^{\circ} \mathrm{C}$ and extension for $1 \mathrm{~min}$ at $72{ }^{\circ} \mathrm{C}$ for all primers. The amplification reaction products were resolved on $1.2 \%$ agarose/TAE gels, separated at $135 \mathrm{mV}$ and visualised by ethidium bromide staining.

Cell lines and cell culture. Six HNSCC cell lines were used for this study. Ho-1-N-1 and Ho-1-U-1 cells were provided by the Japanese Collection of Research Bioresources Cell Bank. HOC313 and HOC621 cells were provided by Prof. Kamata (Hiroshima University, Hiroshima, Japan) (Yokoyama et al, 2001). KOSCC33A and KOSCC25B cells were obtained from Dr SP Hong (Seoul National University, Seoul, South Korea). All cells were maintained in RPMI-1640 or DMEM (Nissui Pharmaceutical Co., Tokyo, Japan) supplemented with $10 \%$ heat-inactivated FBS (Invitrogen) and $100 \mathrm{U} \mathrm{ml}$ penicillin-streptomycin (Gibco, Tokyo, Japan) under $5 \% \mathrm{CO}_{2}$ in air at $37^{\circ} \mathrm{C}$.

Immunofluorescence. Cells grown on coverslips were fixed in $4 \%$ paraformaldehyde for $10 \mathrm{~min}$ at room temperature, rinsed three times with ice-cold PBS and then permeabilised in $0.1 \%$ Triton $\mathrm{X}-100$ in PBS for $15 \mathrm{~min}$ at room temperature. After rinsing three times with PBS, the coverslips were incubated with the primary antibody in 10\% DMEM for $2 \mathrm{~h}$ at room temperature, rinsed three times with PBS and then incubated with anti-mouse Alexa594 ( 1 : 1000; Molecular Probes, Eugene, OR, USA), which served as the secondary antibody. DNA was visualised by DAPI staining. The immunostaining of cell preparations was recorded using an epifluorescence Zeiss Axioplan 2 (Zeiss Inc., Thorwood, NY, USA) microscope attached to a CCD camera.

Proliferation assay. Cells were plated in a 24 -well plate at $5 \times 10^{3}$ cells per well and cultured in DMEM medium. After 1, 2 and 4 days of culture, the cells were trypsinised and counted using a Coulter Counter (Coulter Electronics, Bedfordshire, UK). Each experiment was repeated at least three times in triplicate wells. The growth curves showed the means and standard deviation of the counted cell number.

In vitro invasion assay. The invasive behaviour of cells was measured using a Matrigel invasion assay. Eight-micron cell culture plate inserts (24-well inserts, $8-\mu \mathrm{m}$ pore size; BD Bioscience, Bedford, MA, USA) were coated with $50 \mu$ l Matrigel (1 mg ml; BD Bioscience). All cells were preincubated in media with or without PD173074. One hundred microliters of media containing $2 \times 10^{4}$ cells was added to the upper chamber insert, and $500 \mu \mathrm{l}$ of DMEM was added to the lower chamber. The cells were incubated for $20 \mathrm{~h}$ at $37^{\circ} \mathrm{C}$ in $5 \% \mathrm{CO}_{2}$ humidified air, and cells that passed through the Matrigel were fixed in $10 \%$ paraformaldehyde and subsequently stained with Mayer's haematoxylin. Cells that did not pass through the Matrigel were removed from the insert with a cotton swab. The membrane of the insert was cut from the insert and fixed onto a slide.

The number of invasive cells was evaluated by counting all invading cells under the microscope ( $\times 10$ magnification), and the results were expressed as averages with the standard error. All assays were performed in triplicate.

Migration (wound healing) assay. Two million cells from each group were seeded in $60-\mathrm{mm}$-diameter culture dishes and grown to confluence in complete medium. The cells were then gently scraped with a plastic tip. Photomicrographs were taken at 24 and $48 \mathrm{~h}$ after wound formation.

Subcellular fractionation. Cells grown on $10-\mathrm{cm}$ dishes were washed two times and scraped in ice-cold PBS. The cells were then centrifuged for $30 \mathrm{~s}$ at $12000 \mathrm{~g}$, and the supernatant was discarded. The cells were resuspended in ice-cold lysis buffer containing $10 \mathrm{~mm}$ morpholineethanesulphonic acid (MES; pH 6.2), $10 \mathrm{~mm}$ $\mathrm{NaCl}, 1.5 \mathrm{~mm} \mathrm{MgCl}_{2}, 1 \mathrm{~mm}$ EDTA, $5 \mathrm{M}$ dithiothreitol, 1\% Triton $\mathrm{X}-100$ and protease inhibitors. After a 5-min centrifugation step, the supernatant containing the cytoplasmic fraction was removed. The remaining nuclear pellet was washed once with washing buffer 
(lysis buffer without Triton X-100) and lysed in ice-cold extraction buffer (25 mm Tris-HCl (pH 10.5), 1 mm EDTA, $0.5 \mathrm{M} \mathrm{NaCl}, 5 \mathrm{~mm}$ $\beta$-mercaptoethanol, $0.5 \%$ Triton $\mathrm{X}-100)$. The resultant supernatant containing the nuclear fraction was removed.

Western blotting. The cells were lysed in a buffer containing $50 \mathrm{~mm}$ Tris ( $\mathrm{pH}$ 7.5), $250 \mathrm{~mm} \mathrm{NaCl}, 0.1 \%$ Triton X (Sigma Chemical Co., St Louis, MO, USA), 1 mм EDTA, 50 mм NaF and six proteinase inhibitors (DTT, PMSF, Banadate, TPCK, TLCK and PIN). The protein concentration was determined using the Bradford protein assay (Bio-Rad, Richmond, CA) with bovine serum albumin (Sigma) as the standard. Twenty micrograms of protein was solubilised in Laemmli's sample buffer by boiling and subjected to $10 \%$ SDS-PAGE electrophoresis, followed by electroblotting onto a nitrocellulose membrane (Schleicher \& Schuell, Dasse, Germany). The filter was blocked for $1 \mathrm{~h}$ at room temperature with PBS buffer ( $137 \mathrm{~mm} \mathrm{NaCl}, 8.1 \mathrm{~mm} \mathrm{Na}_{2} \mathrm{HPO}_{4}$. $\left.12 \mathrm{H}_{2} \mathrm{O}, 2.68 \mathrm{~mm} \mathrm{KCl}, 1.47 \mathrm{~mm} \mathrm{KH}_{2} \mathrm{PO} 4\right)$ containing non-fat dry milk powder. The primary antibodies were diluted in PBS containing $5 \%$ non-fat dry milk powder and incubated overnight at $4{ }^{\circ} \mathrm{C}$, and the cells were then washed and incubated with the secondary antibody for $1 \mathrm{~h}$ at room temperature. The immunocomplex was visualised with an enhanced chemiluminescence HRP substrate for western blotting (Western Lightning Plus ECL; Perkin-Elmer, Waltham, MA, USA) using a Molecular Imager machine (Bio-Rad, Carlsbad, CA, USA). Blots were stripped in $50 \mathrm{~mm}$ Tris ( $\mathrm{pH} \mathrm{7.5)}$ and $10 \mathrm{M}$ urea at $55^{\circ} \mathrm{C}$ for $20 \mathrm{~min}$ before reprobing.

\section{RESULTS}

FGFR1 expression and its correlation with clinicopathological findings. To examine the role of FGFR1 in the progression of HNSCC, we examined the immunohistochemical expression of FGFR1 and its correlation with the clinicopathological findings in 100 HNSCC cases. Here, we classified low-grade HNSCC as grades I and II and high-grade HNSCC as grades III and IV, according to the classification described by Anneroth et al (1987) (Table 1). The correlations between features of FGFR1 expression and the clinicopathological findings, including nuclear polymorphism, pattern of invasion and histopathological grade of HNSCC, are summarised in Table 2. Fibroblast growth factor receptor 1 was

\begin{tabular}{|c|c|}
\hline Feature & HNSCC $(n=100)$ \\
\hline Mean age (range, years) & $58.93(22-92)$ \\
\hline \multicolumn{2}{|l|}{ Sex } \\
\hline $\begin{array}{l}\text { Male } \\
\text { Female }\end{array}$ & $\begin{array}{l}27(27 \%) \\
73(73 \%)\end{array}$ \\
\hline \multicolumn{2}{|c|}{ Histopathological grade } \\
\hline $\begin{array}{l}\text { Well/moderate } \\
\text { Poor }\end{array}$ & $\begin{array}{l}69 \text { (69\%) } \\
31 \text { (31\%) }\end{array}$ \\
\hline \multicolumn{2}{|l|}{ FGFR1 expression } \\
\hline $\begin{array}{l}\text { Cytoplasm + membrane } \\
\text { Nuclear }+ \text { membrane } \\
\text { Negative }\end{array}$ & $\begin{array}{l}28(28 \%) \\
26(26 \%) \\
46(46 \%)\end{array}$ \\
\hline
\end{tabular}

highly expressed in 54 (54\%) of 100 HNSCC cases (Figure 1A and Table 2). Interestingly, FGFR1 expression significantly correlated with nuclear polymorphism (Figure 1B), pattern of invasion (Figure 1C) and histological differentiation (Figure 1D). Fibroblast growth factor receptor 1 expression was also significantly correlated with the number of mitoses per high-power field (data not shown).

Nuclear localisation of FGFR1 in OSCC cases. Recently, it was shown that FGFR1, a plasma membrane-associated protein, translocates to the cell nucleus along with its ligand bFGF and stimulates a multigene program (Stachowiak et al, 2003). In this study, the immunohistochemical staining results for FGFR1 showed two distinct patterns of FGFR1 expression; FGFR1 was either expressed in the cytoplasm and membrane or in the nucleus and membrane (Figure 2A). We next analysed the correlation between nuclear FGFR1 expression and clinicopathological features of oral squamous cell carcinoma (OSCC). Interestingly, FGFR1 expression was significantly correlated with nuclear polymorphism (Figure 2B), pattern of invasion (Figure 2C) and histological differentiation (Figure 2D).

Expression of FGFR1 in HNSCC cell lines. To investigate the correlation between FGFR1 and EMT, we examined the expression of FGFR1, E-cadherin and EMT master genes, including Vimentin, Snail1, Snail2, ZEB1, ZEB2 and $\alpha$-SMA, in six HNSCC cell lines. Among these cell lines, HOC313, KOSCC25B and KOSCC 33 A cells showed a loss of E-cadherin expression and prominent expression of Snail1, Snail2, ZEB1 and ZEB2 (Figure 3B), which is consistent with previous studies showing that HOC313, KOSCC25B and KOSCC 33A cells demonstrate spindle morphology, high invasive activity and elevated expression of Snail without E-cadherin expression (Yokoyama et al, 2001, 2003; Taki et al, 2003; Hong et al, 2009). As a result, HOC313, KOSCC25B and KOSCC 33A cells are considered EMT-induced cell lines. In contrast, three other HNSCC cell lines (HOC621, Ho-1-N-1 and Ho-1-U-1) showed cobblestone-like morphology (Figure 3A) with strong E-cadherin expression but weak Snail1, Snail2, ZEB1, ZEB2 and Vimentin expression (Figure 3B). Among the cell lines tested, FGFR1 was strongly expressed in the EMT-induced lines but was very weakly expressed in non-EMT-induced lines (Figure 3B).

We also examined the localisation of FGFR1 expression in HOC313, KOSCC25B and KOSCC33A cells by performing immunofluorescent staining (Figure 3C) and western blotting for cytoplasmic and nuclear fractions (Figure 3D). As shown in Figures 3C and D, FGFR1 was expressed strongly in the nucleus of KOSCC25B cells, partially in the nucleus of HOC313 cells and weakly in the nucleus of KOSCC33A cells.

PD173074 suppresses the growth and invasion of EMT-induced cancer cells. Numerous inhibitors of FGFR1 activation have previously been identified. Here, we examined PD173074, an FGFR1-selective inhibitor and a known inhibitor of FGFR1 kinase activity in vitro. This drug showed an $\mathrm{IC}_{50}$ of approximately $25 \mathrm{~nm}$ and inhibited the autophosphorylation of FGFR1 in a dose-dependent manner with an $\mathrm{IC}_{50}$ ranging from 1 to $5 \mathrm{~nm}$ (Mohammadi et al, 1998). To examine the utility of PD173074 as a therapeutic for HNSCC, we treated EMTinduced cell lines (HOC313, KOSCC25B and KOSCC33A) with $15 \mathrm{~nm}$ PD173074 and counted the number of cells at days 1, 2 and 4 after treatment. PD173074 treatment suppressed the cell growth of EMT-induced cell lines (Figure 4A-C). Furthermore, using migration and Matrigel invasion assays, we found that PD173074 strongly suppressed the ability of HOC313, KOSCC25B and KOSCC33A cells to invade and migrate (Figure $5 \mathrm{~A}$ and $\mathrm{B}$ ). 
A

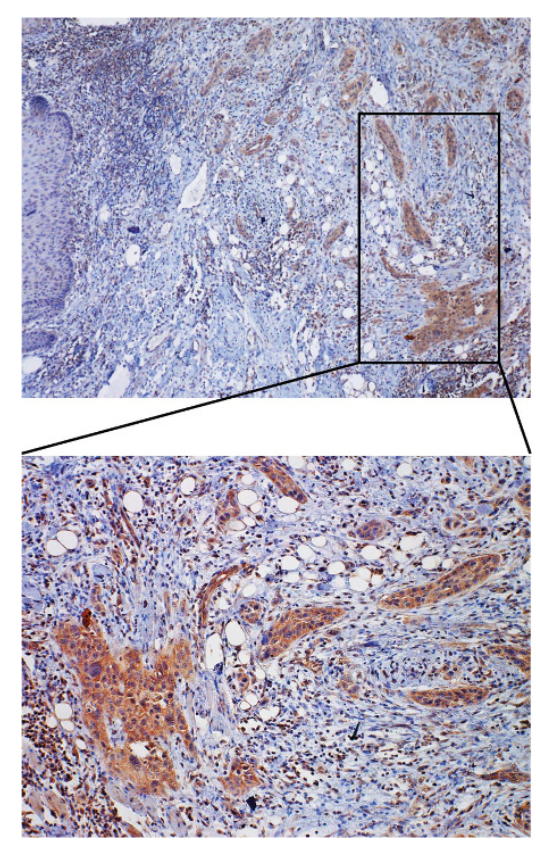

B

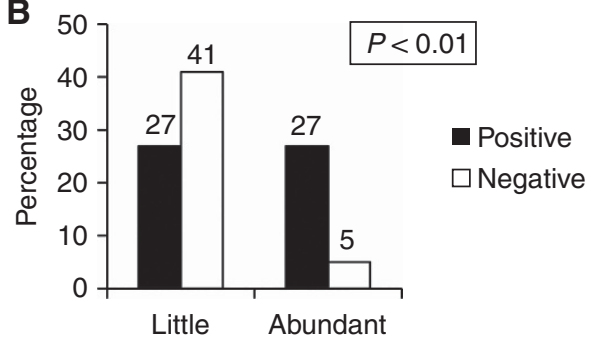

Nuclear polymorphism
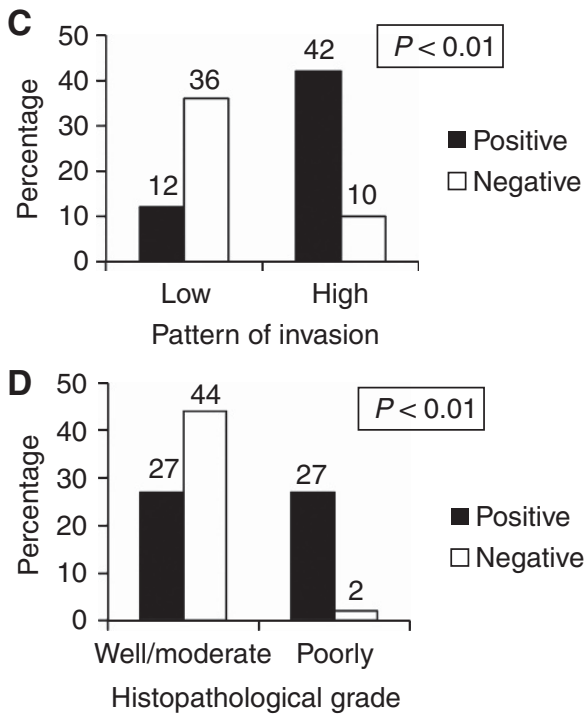

Figure 1. Expression of FGFR1 and its correlation to clinicopathological findings in HNSCC. (A) Immunohistochemical staining of FGFR1 in HNSCC. The upper panel shows a lower magnification $(\times 40)$, and the lower panel shows a higher magnification $(\times 200)$. (B) Correlation between FGFR1 expression and nuclear polymorphism (little and abundant). The graph shows the percentage of cases with positive or negative expression of FGFR1 in each group (little or abundant nuclear polymorphism). (C) Correlation between FGFR1 expression and the pattern of invasion (low grade and high grade). The graph shows the percentage of cases with positive or negative expression of FGFR1 in each group (high- or low-grade invasive pattern). (D) Correlation between FGFR1 expression and the histopathological grade (well, moderate and poorly differentiated). The graph shows the percentage of cases with positive or negative expression of FGFR1 in each group (well and moderate or poorly expressed for each histopathological grade).

PD173074 induces MET through MAPK, GSK3 $\beta$ and AP-1 activity. Because we observed suppressed invasion in EMT-induced HNSCC cell lines, we investigated the expression of master EMT genes following PD173074 treatment in HOC313 cells. Interestingly, PD173074 treatment concurrently reduced Snail1 and Snail2 expression but induced E-cadherin expression (Figure 6A). These results were also confirmed at the protein level (Figure 6B). Furthermore, we assessed invasion in vitro using Matrigel as a surrogate basement membrane, as cancer cell interactions with the basement membrane matrix are critical, particularly for the peritoneal invasive route. Therefore, we examined the expression of MMPs and found that the expression levels of several MMPs (MMP3, MMP10, MMP12 and MMP13) were reduced in PD173074-treated HOC313 cells, whereas MMP2 and MMP11 expression remained unchanged (Figure 6A).

According to the GenBank database (National Center for Biotechnology Information, Bethesda, MD, USA), the genes encoding several EMT master markers and MMPs possess the same activator protein-1 (AP-1) binding site (Figure 6D). In this study, we sought to assess whether several pathways related to FGFR1 activation may result in the reduced expression of Snaill and several MMPs, as well as the increased expression of E-cadherin. PD173074 treatment inhibited the activation of ERK1/2, p38 and c-Jun (Figure 7A) but stimulated the phosphorylation of GSK3 $\beta$ (Figure 7B). However, PD173074 treatment did not affect the activity of Akt (Figure 7A). These results suggested that PD173074 suppressed the phosphorylation of ERK1/2 and p38, which led to inhibition of c-Jun, a component of AP-1. To better understand the role of AP-1 in MET, we knocked down c-Jun expression by transfecting c-Jun siRNA into HOC313 cells (Figure 7C) and examined the resultant E-cadherin and Snaill expression. Interestingly, Snaill expression was reduced and E-cadherin expression was upregulated $72 \mathrm{~h}$ after c-Jun knockdown (Figure 7D).

Moreover, we observed that PD173074 treatment changed the morphology of HOC313 cells from a spindle-like shape to a cobble stone-like shape (Figure 6C). The morphology of KOSCC25B and KOSCC $33 \mathrm{~A}$ cells also changed from a spindle- to a cobble stonelike shape, but the mechanism of MET induction in these cells differs from that of HOC313 cells and requires further investigation. Figure 6E clearly shows that PD173074 treatment induced the formation of adherent junctions within 5 days.

\section{DISCUSSION}

Fibroblast growth factor receptors have a key role in the proliferation and differentiation of tumour cells, and recent studies have focused on the role of the FGFR family (especially FGFR3) in carcinogenesis (Lamont et al, 2011). In lung and prostate cancer, 
A
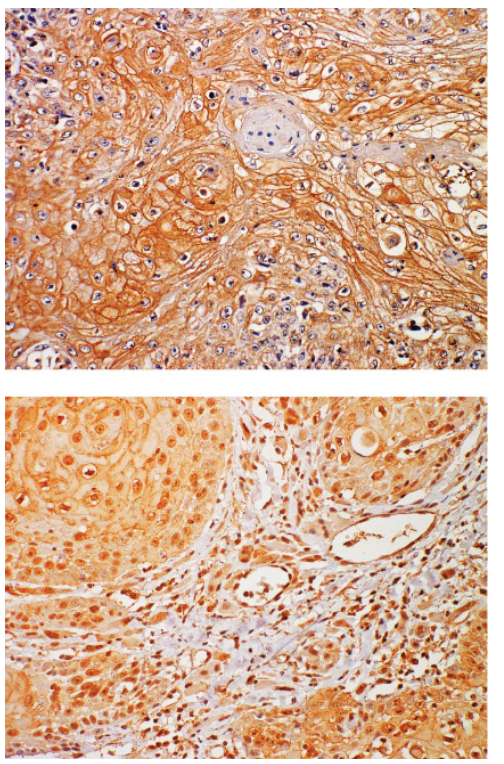
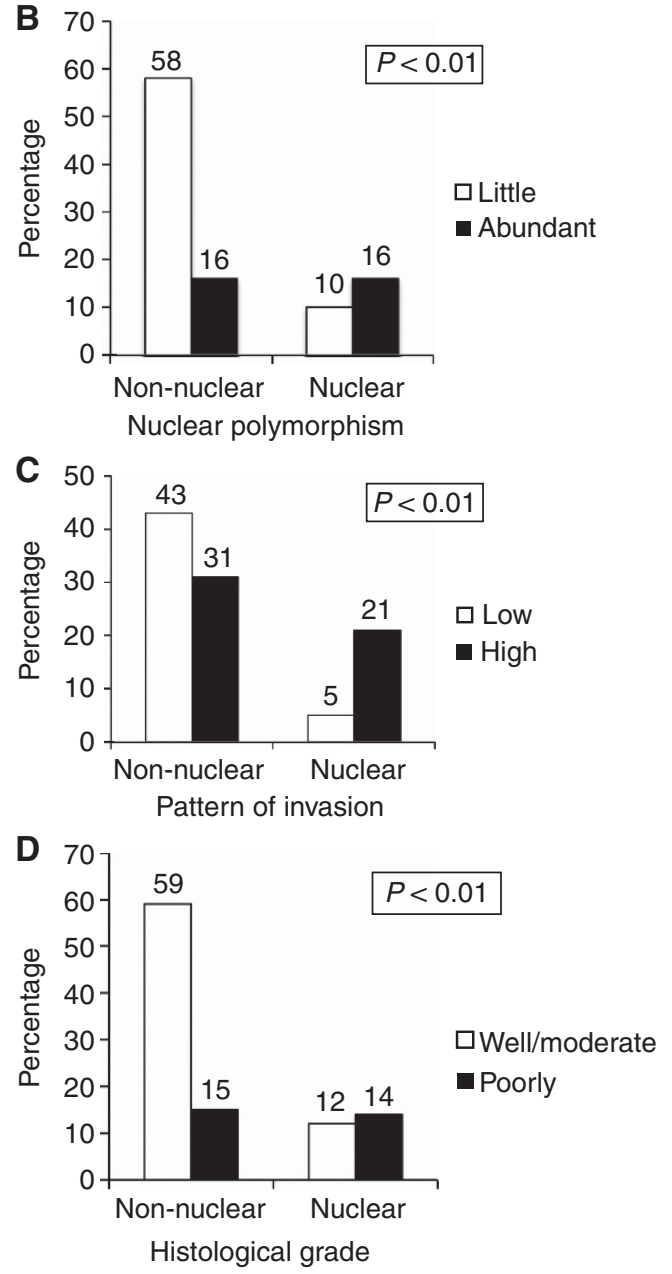

Figure 2. Expression of nuclear FGFR1 and its correlation with clinicopathological findings in HNSCC. (A) Positive expression pattern of FGFR1 at higher magnification ( $\times 200$ ). The upper panel shows positive expression of FGFR1 in the membrane and cytoplasm of cancer cells. The lower panel shows positive expression of FGFR1 in the nuclei of cancer cells. (B) Correlation between FGFR1 expression in the nucleus and nuclear polymorphism (little and abundant). The graph shows the percentage of cases with nuclear or non-nuclear expression of FGFR1 in each group (high or low nuclear polymorphism). (C) Correlation between FGFR1 expression and the pattern of invasion (low grade and high grade). The graph shows the percentage of cases with nuclear or non-nuclear expression of FGFR-1 in each group (high- or low-grade invasive pattern).

(D) Correlation between nuclear FGFR1 expression and the histopathological grade (well, moderate or poorly differentiated). The graph shows the percentage of cases with nuclear or non-nuclear expression of FGFR1 in each group (well and moderate or poorly expressed for each histopathological grade).

FGFR1 is implicated as an oncogene whose expression is increased in comparison to normal tissue (Giri et al, 1999; Behrens et al, 2008). Furthermore, premalignant prostate cells expressing activated FGFR1 have been shown to drive the progression to malignancy (Acevedo et al, 2007), yet little is known about the expression and precise role of FGFR1 in head and neck cancer. In this study, we observed high levels of FGFR1 expression by immunohistochemistry in a large number of HNSCC cases and demonstrated that FGFR1 was overexpressed in $54 \%$ of HNSCC cases as well as a high proportion of HNSCC cell lines, especially EMT-induced cell lines. Furthermore, FGFR1 expression was localised in the membrane, cytoplasm and nucleus of cancer cells. We found that FGFR1 expression was increased in poorly differentiated HNSCC, which agrees with previously reported findings from a number of different types of carcinoma, such as lung cancer (Behrens et al, 2008) and prostate cancer (Giri et al, 1999).

Recent studies have also shown that upon stimulation, cells can endocytose FGFR1 into the cytosol, at which point the receptor translocates to the nucleus along with its ligand, bFGF. Within the nucleus, FGFR1 functions as a general transcriptional regulator that activates and stimulates multigene programs for cell growth and differentiation. Stachowiak et al (1997) demonstrated that nuclear FGFR1 stimulated the transition from $G_{0} / G_{1}$ to $S$ phase of the cell cycle. Moreover, nuclear FGFR1 executes the release of CBP (CREB-binding protein) from its inactive complex with RSK1 (Fang et al, 2005), a process shown to upregulate gene activities associated with cell differentiation. Furthermore, the protease granzymeB (GrB) has been shown to be responsible for the cleavage of FGFR1 and the nuclear localisation of FGFR1 cleavage, leading to the invasion of breast cancer cells into the stroma (Chioni and Grose, 2012). Our findings showed that a significant increase in FGFR1 nuclear localisation in SCC cells correlated with high-grade histopathology, abundant nuclear polymorphism and a high-grade invasion pattern. Conversely, Behrens et al (2008) found that the nuclear expression of FGFR1 correlated significantly with worsened overall survival and recurrence-free survival. We suspect that nuclear FGFR1 may promote invasion and metastasis and that the aberrant nuclear expression of FGFR1 could serve as a marker to predict the malignant behaviour of HNSCC. 
A

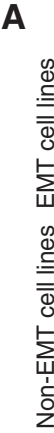

HOC313

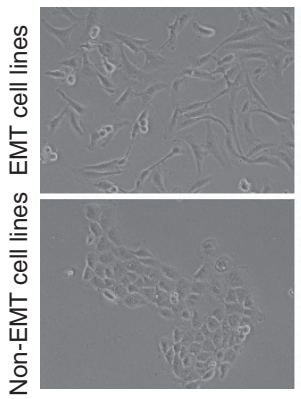

HOC621

C
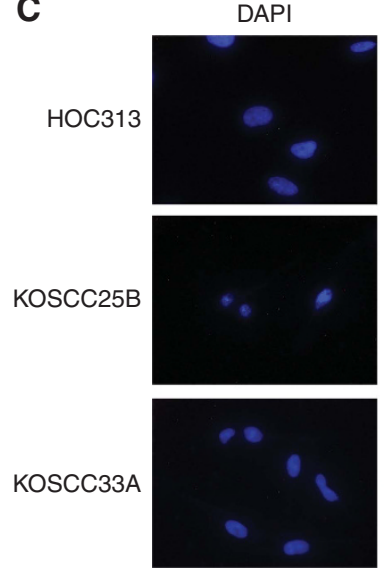

KOScC25B

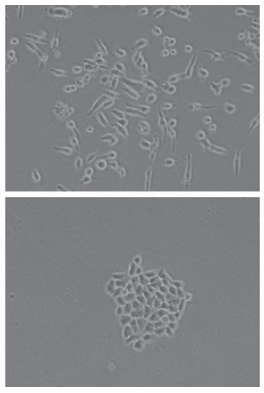

Ho-1-N-1
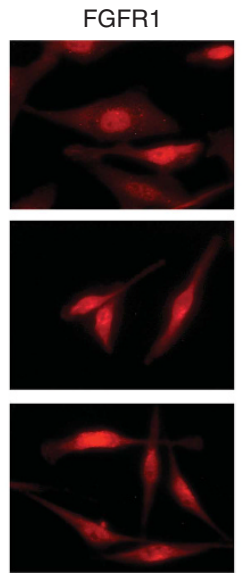

KOScC33A

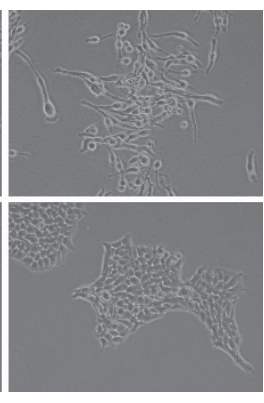

Ho-1-U-1
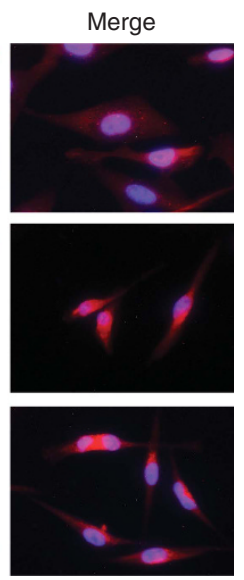

B

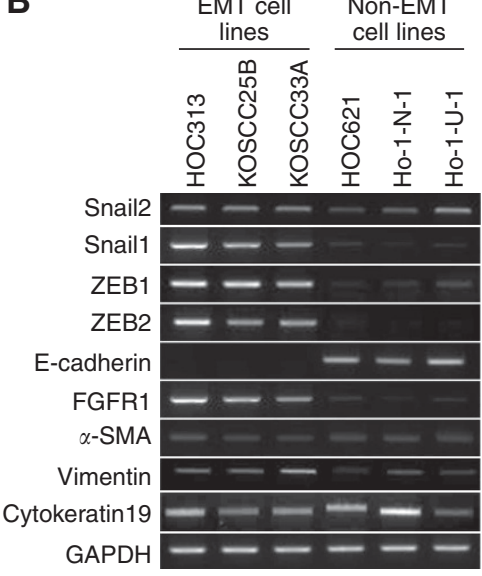

D

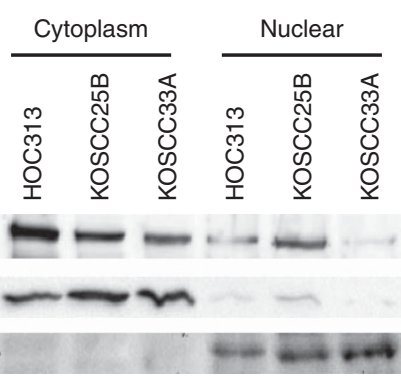

Figure 3. Expression of FGFR1 in HNSCC cell lines. (A) Morphology of HNSCC cells. The upper panel shows the morphology of EMT-induced cells (HOC313, KOSCC25B and KOSCC33A), and the lower panel shows the morphology of non-EMT-induced cells (HOC621, Ho-1-N-1 and Ho-1-U1). (B) The expression of FGFR-1, N-cadherin, E-cadherin, Snail-1, Snail-2 and $\alpha$-SMA was examined by reverse transcription-polymerase chain reaction (RT-PCR) in EMT-induced cells (HOC313, KOSCC25B and KOSCC33A) and non-EMT-induced cells (HOC621, Ho-1-N-1 and Ho-1-U-1). GAPDH expression was used as a positive control. (C) Localisation of FGFR1 expression was examined by immunofluorescent staining in HOC313, KOSCC25B and KOSCC33A cells. (D) The localisation of FGFR1 expression was examined by western blotting of the subcellular fraction of EMT-induced cells (HOC313, KOSCC25B and KOSCC33A), and GAPDH and LaminB1 expression was used as a positive control. Abbreviation: DAPI =4',6-diamidino-2-phenylindole.
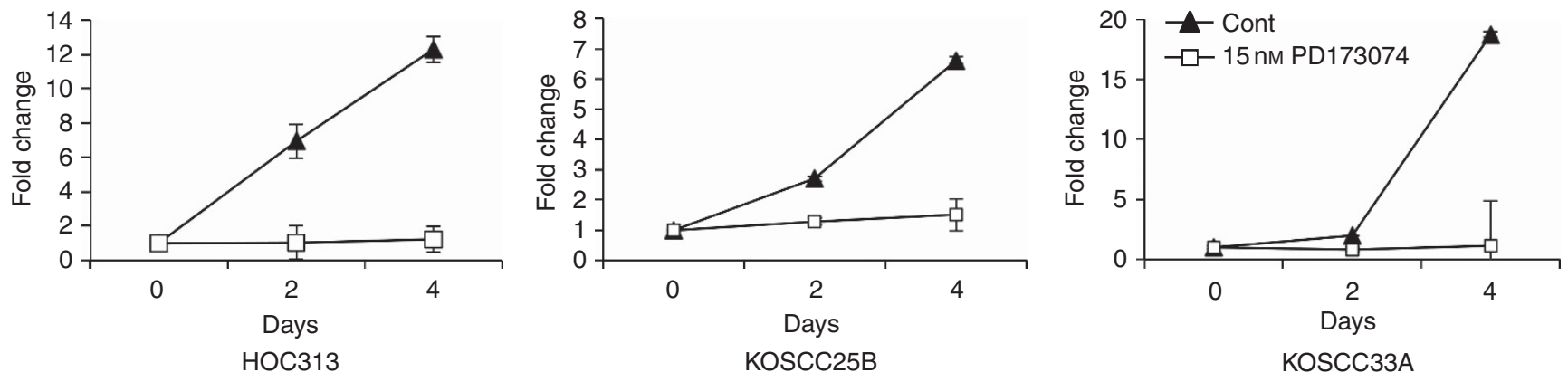

Figure 4. A decrease in cell growth was measured using proliferation assays with HOC313 cells $(P=0.003)$ or KOSCC25B cells $(P=0.001)$ and KOSCC33A cells $(P=0.003)$ upon treatment with $15 \mathrm{~nm}$ PD173074. Five thousand cells were plated in each well and cultured in Dulbecco's modified Eagle's medium (DMEM). After 1, 2 and 4 days of treatment, cells were trypsinised and counted. Similar results were obtained in three independent experiments. Data represent the means \pm s.d. $(n=3)$.

Small-molecule inhibitors (PD173074, tyrosine kinase inhibitor (TKI)-258 and SU5402) have recently been used successfully to target FGFR3 in multiple myeloma and urothelial carcinoma both in vitro and in animal models (Grand et al, 2004; Lamont et al, 2011). PD173074, a synthetic compound of pyrido-[2,3-d] and a highly selective TKI of FGFR1, competes with ATP binding sites located in the intracellular domain of FGFR1 (Mohammadi et al, 1998) and was used in this study as a selective inhibitor of FGFR1.
In this study, PD173074 treatment suppressed the growth, migration and invasion of EMT-induced HNSCC cell lines (Figures 4 and 5). Moreover, PD173074 treatment also reduced the expression of Snail, MMP3, MMP10, MMP12 and MMP13, but induced the expression of E-cadherin. On the basis of the GenBank database, we found that the promoter regions of SNAI1, SNAI2, $M M P 3, M M P 10, M M P 12$ and $M M P 13$ contain an AP-1 binding site (Figure 6D), whereas MMP2 and MMP11 do not contain a conserved AP-1 site. The AP-1 transcription factor is formed by 
A

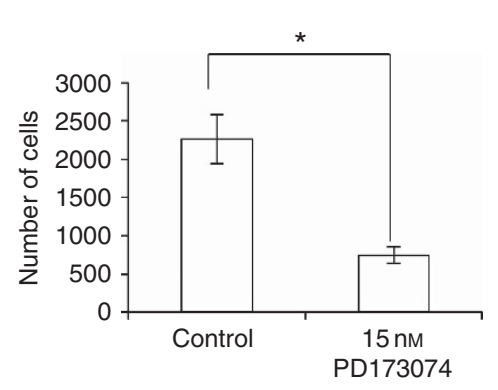

HOC313

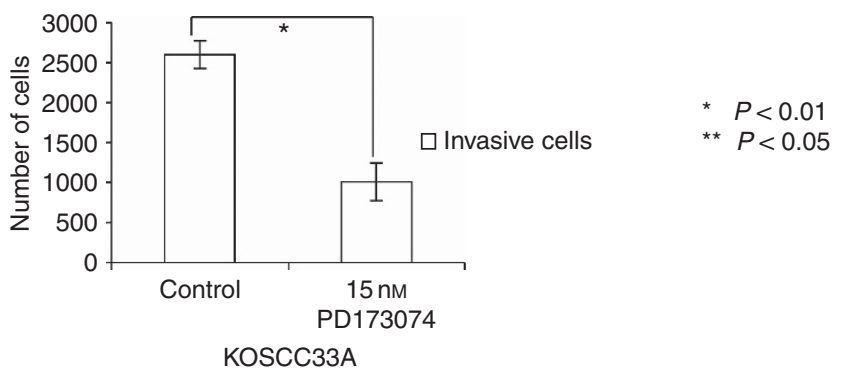

B
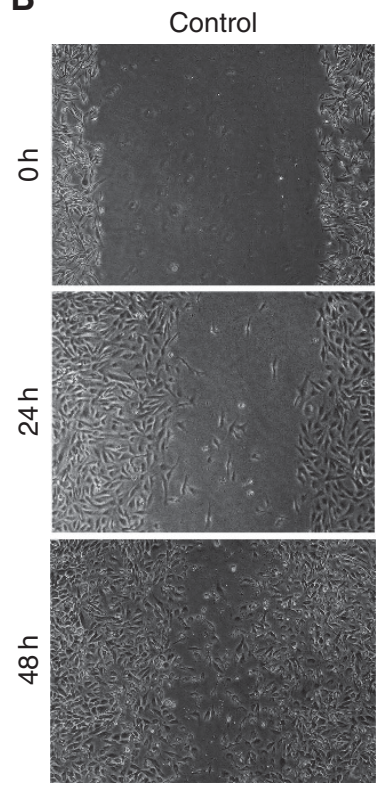

15 nм PD173074
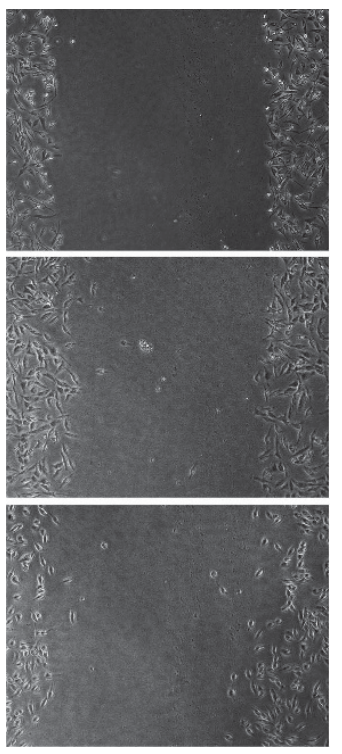

Figure 5. PD173074 inhibited cancer cell invasion and migration. (A) A decrease in invasive ability measured using the Matrigel invasion assay in HOC313 cells upon treatment with $15 \mathrm{~nm}$ PD173074 after $20 \mathrm{~h}$ incubation. ${ }^{\star} P<0.01$; ${ }^{\star *} P<0.05$. Twenty thousand cells in $100 \mu \mathrm{l}$ Dulbecco's modified Eagle's medium (DMEM) with or without PD173074 were plated in Matrigel-coated inserts with an $8 \mu \mathrm{m}$ pore size. Following culture in $500 \mu \mathrm{l}$ DMEM for $20 \mathrm{~h}$, cells on the lower surface of the insert membrane were fixed, stained with haematoxylin and counted. Similar results were obtained in three independent experiments. Data represent the means \pm s.d. $(n=3)$. (B) A decrease in migration ability was measured using the migration wound healing assay in HOC313 cells upon treatment with $15 \mathrm{~nm}$ PD173074 for 24 or $48 \mathrm{~h}$. Two million cells were plated $24 \mathrm{~h}$ before PD173074 treatment and were then scraped with a plastic tip. Photomicrographs were taken at 24 and $48 \mathrm{~h}$ after wound formation.

either the homodimerisation of two jun proteins (c-jun, JunB, JunD) or the heterodimerisation of jun and fos proteins through the 'leucine zipper', and this transcription factor regulates a number of genes that drive tumour promotion and progression (Angel and Karin, 1991). An alteration in AP-1 composition either directly or indirectly regulates transactivation and DNA-binding activity, which in turn pushes normal cells into a premalignant or malignant state. Previous studies have shown that a component of AP-1 is highly expressed in malignant cervical tissues (Prusty and Das, 2005), and the basal activity level of AP-1 is known to be important for normal cell proliferation and cell survival. However, overactive c-Jun and c-Fos have recently been recognised to have a key role in malignant transformation (Shaulian and Karin, 2001).

In this study, the expression of several MMPs (MMP3, MMP10, MMP12 and MMP13), which contain an AP-1 binding site, was reduced following PD173074 treatment in comparison to control cells. Conversely, the expression of MMP2 and MMP11 remained unchanged in response to PD173074 treatment (Figure 6A). In general, the expression of MMPs is regulated by transcription factors that are stimulated by growth factors, cytokines and chemical agents such as phorbol esters, physical stress, oncogenic transformation and cell-cell and cell-ECM interactions. The downregulation of MMPs (MMP3, MMP7, MMP9, MMP12 and MMP13) following PD173074 treatment in this study may be related to AP-1, as the results in Figures $7 \mathrm{~A}$ and $\mathrm{B}$ suggest that PD173074 inhibited ERK1/2 and p38 activation, which diminished the phosphorylation of c-Jun, a component of AP-1. Furthermore, these actions inhibited the transcriptional induction of AP-1-dependent genes, such as MMP3, MMP12 and MMP13.

In addition, cellular changes driven by EMT that generate mesenchymal-like cancer cells are thought to have a major role in tumour progression. The central role of E-cadherin loss in
EMT has been illustrated in many studies (Yilmaz and Christofori, 2011), and the expression of E-cadherin and Snail, a transcription factor described as a direct repressor of E-cadherin, inversely correlates with the prognosis of patients suffering from breast cancer or OSCC. Furthermore, loss of E-cadherin expression is frequently observed during tumour progression in most epithelial cancers (Cavallaro and Christofori, 2004), and we previously demonstrated that methylation of E-cadherin is involved in invasion and metastasis in HNSCC (Kudo et al, 2004).

Moreover, the induction of Snaill expression has been observed in all previously reported EMT processes (Nieto, 2002; Barrallo-Gimeno, 2005), and increased Snail1 levels have been correlated with more invasive tumour types (Cano et al, 2000). While repressing epithelial gene expression, Snail proteins activate the expression of the mesenchymal proteins fibronectin and vitronectin (Cano et al, 2000; Olmeda et al, 2007). Snaill also drives the expression of the ECM proteins type III and V collagen (Moreno-Bueno et al, 2006). Here, we found that PD173074 suppressed the expression of Snaill and concurrently induced the expression of E-cadherin (Figures 6A and B). On te basis on the GenBank database, Snail1 and Snail2 also possess AP-1 binding sites in their promoters (Figure 6D); however, the relationship between AP-1 and Snail in MET has not yet been reported. To determine whether there was a relationship between AP-1 and Snaill expression, we knocked down c-Jun and examined the resultant expression of E-cadherin and Snaill. Interestingly, Snail1 expression was reduced, whereas E-cadherin expression was induced, $72 \mathrm{~h}$ following knockdown of c-Jun.

In addition, Snail is regulated according to its subcellular localisation through GSK3 $\beta$-mediated phosphorylation. GSK3 $\beta$ binds to and phosphorylates Snail at two consensus motifs to dually regulate the function of this protein, and the phosphorylation by GSK3 $\beta$ leads to the degradation of Snail (Zhou et al, 2004). 
A

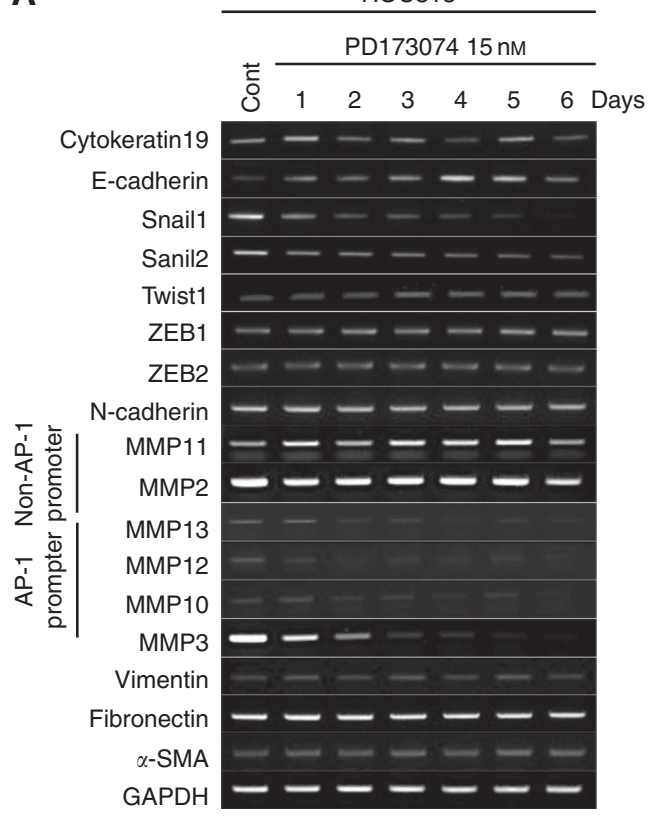

E

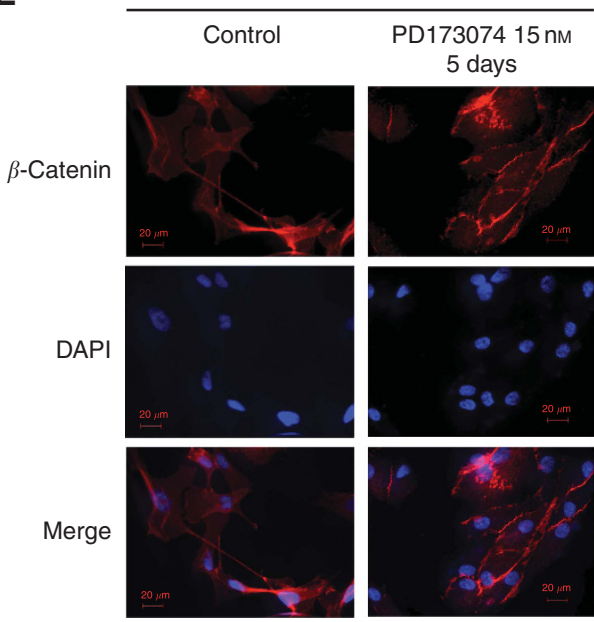

B

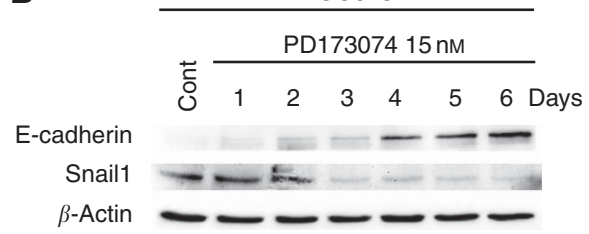

C

HOC313

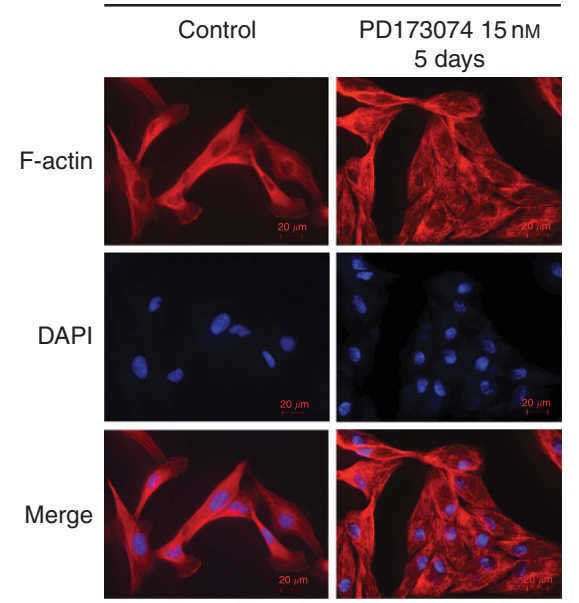

D

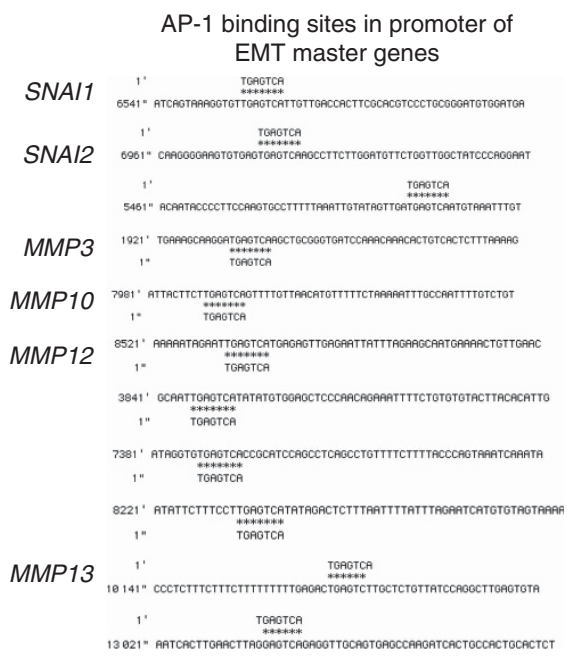

Figure 6. PD173074 induced MET. (A) The expression of EMT master genes, MMPs and major epithelial markers was examined by reverse transcription-polymerase chain reaction (RT-PCR) in HOC313 cells upon treatment without or with 15 nm PD173074B after 1, 2, 3, 4, 5 and 6 days. GAPDH expression was used as a positive control (Cont). (B) The expression of E-cadherin and Snail-1 was analysed by western blotting upon treatment without or with $15 \mathrm{~nm}$ PD173074B for 1, 2, 3, 4, 5 and 6 days. Anti- $\beta$-actin was used as a loading control. (C) Cell morphological changes. Upper panel, cell morphology was analysed by fluorescent microscopy according to the immunolocalisation of F-actin at day 5 with or without PD173074 treatment. (D) Activator protein-1 (AP-1) binding sites in the promoter of EMT master genes. (E) $\beta$-Catenin expression and adherent junctions in HOC313 cells were examined by immunofluorescent staining at day 5 after PD173074 treatment (15 nM). DAPI, 4',6-diamidino-2phenylindole.

Our results indicate that Snaill expression was inhibited, whereas E-cadherin expression was increased and formed adherent cell-cell junctions. We speculate that this process may be regulated by two pathways. First, PD173074 may have suppressed ERK1/2 and p38 activation, which inhibited c-Jun phosphorylation and thus reduced Snaill expression; second, PD173074 may have stimulated GSK3 $\beta$ activity, which could have inhibited the transcription of Snail1 but induced parallel E-cadherin expression.

As our results have shown, the interaction between an epithelial cell and its neighbouring cell at adherent junctions contributes to the regulation of cell shape, migration, proliferation and differentiation. The chief components of adherent junctions in epithelial cells are E-cadherin and $\beta$-catenin (Gumbiner, 2005). Loss of cellular adhesion is frequently observed during tumour metastasis, and we observed that HOC313 cells with a spindle shape not only adopted a cobblestone-like morphology (Figure 6C) but also showed increased E-cadherin expression (Figure 6A and B) to form adherent junctions between cells in response to PD173074 treatment (Figure 6E). This phenomenon may suppress the invasive ability of HOC313 cells.

On the basis of our results, we speculate that PD173074 may alter the characteristics of EMT-induced cells towards MET induction, in an attempt, thereby controlling malignant behaviours such as the growth, invasion and metastasis of cancer cells. Thus, PD173074 may potentially represent an approach for the treatment of HNSCC. 
A

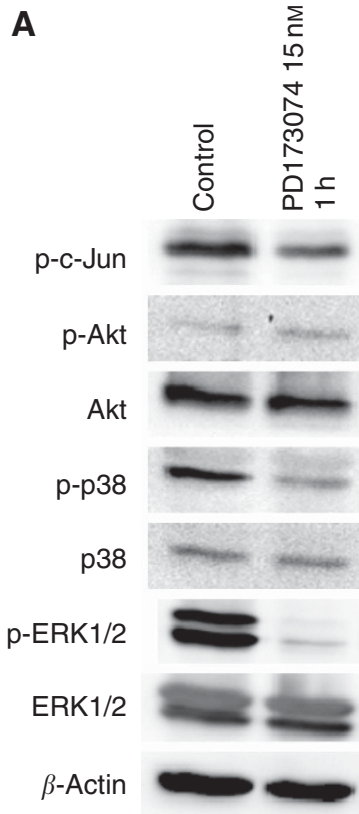

B
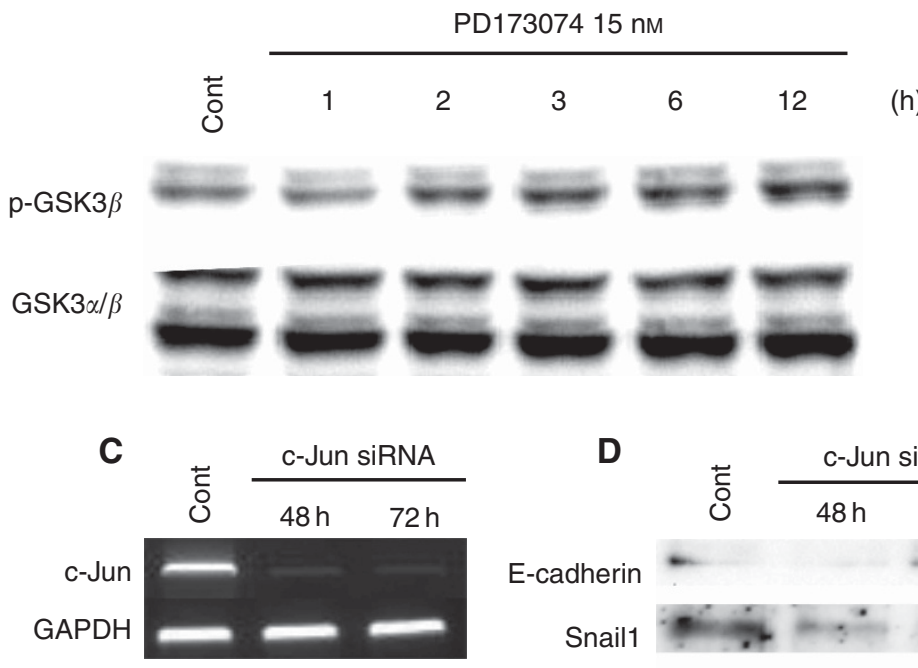

(h)

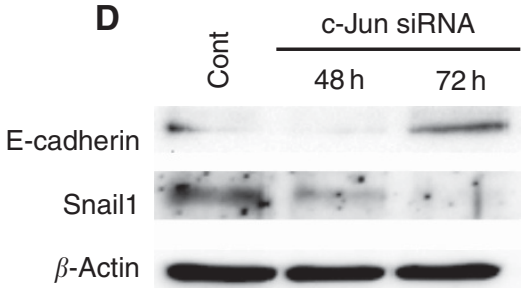

Figure 7. PD173074 induced MET through mitogen-activated protein kinase (MAPK) and glycogen synthase kinase $3 \beta$ (GSK3 $\beta$ ). (A) HOC313 cells were pretreated with $10 \mathrm{~nm}$ bFGF for $10 \mathrm{~min}$ and were then further treated with PD173074 (15 nM) for $1 \mathrm{~h}$. The phosphorylation of ERK1/2, p38, c-Jun and Akt was examined by western blotting. Anti- $\beta$-actin was used as a loading control (Cont). (B) HOC313 cells were pretreated with $10 \mathrm{~nm}$ bFGF for $10 \mathrm{~min}$ and were then further treated with PD173074 (15 nM) for 1, 2, 3, 6 and $12 \mathrm{~h}$. The phosphorylation of GSK3 $\beta$ was examined by western blotting. Anti-GSK $3 \alpha, \beta$ were used as loading controls. (C) The expression of c-Jun was examined by reverse transcription-polymerase chain reaction (RT-PCR) after 48 and $72 \mathrm{~h}$ of c-Jun siRNA treatment in HOC313 cells. GAPDH expression was used as a positive control. (D) The expression of Snail 1 and E-cadherin was analysed by western blotting after 48 and $72 \mathrm{~h}$ of c-Jun siRNA treatment in HOC 313 cells. Anti- $\beta$-actin was used as a loading control.

\section{ACKNOWLEDGEMENTS}

This study was supported in part by grants-in-aid from the Ministry of Education, Science and Culture of Japan to PTN, YK and TT.

\section{REFERENCES}

Acevedo VD, Gangula RD, Freeman KW, Li R, Zhang Y, Wang F, Ayala GE, Peterson LE, Ittmann M, Spencer DM (2007) Inducible FGFR-1 activation leads to irreversible prostate adenocarcinoma and an epithelial to mesenchymal transition. Cancer Cell 12: 559-571.

Angel P, Karin M (1991) The role of Jun, Fos and the AP-1 complex in cell proliferation and transformation. Biochem Biophys Acta 1072: s129-157.

Anneroth G, Batsakis J, Luna M (1987) Review of the literature and a recommended system of malignancy grading in oral squamous cell carcinomas. Scant J Dent 95: 229-249.

Barrallo-Gimeno A, Nieto MA (2005) The Snail genes as inducers of cell movement and survival: implications in development and cancer. Development 132: 3151-3161.

Behrens C, Lin HY, Lee JJ, Raso MG, Hong WK, Wistuba II, Lotan R (2008) Immunohistochemical expression of basic fibroblast growth factor and fibroblast growth factor receptors 1 and 2 in the pathogenesis of lung cancer. Clin Cancer Res 14: 6014-6022.

Cano A, Perez-Moreno M, Rodrigo I, Locascio A (2000) The transcription factor Snail controls epithelial-mesenchymal transitions by repressing E-cadherin expression. Nat Cell Biol 2: 76-83.

Cavallaro U, Christofori G (2004) Cell adhesion and signaling by cadherins and Ig-CAMs in cancer. Nat Rev Cancer 4: 118-132.

Chaffer LC, Weinberg RA (2011) A perspective on cancer cell metastasis. Science 331: 1559-1564.

Chioni AM, Grose R (2012) FGFR1 cleavage and nuclear translocation regulates breast cancer cell behavior. J Cell Biol 197: 801-817.
Dailey L, Ambrosetti D, Mansukhani A, Basilico C (2005) Mechanisms underlying differential responses to FGF signaling. Cytokine Growth Factor Rev 16: 233-247.

Fang X, Stachowiak EK, Dunham-Ems SM, Klejbor I, Stachwiak MK (2005) Control of CREB-binding protein signaling by nuclear fibroblast growth factor receptor-1. J Biol Chem 280: 28451-28462.

Giri D, Ropiquet F, Ittmann M (1999) Alterations in expression of basic fibroblast growth factor (FGF) 2 and its receptor FGFR-1 in human prostate cancer. Clin Cancer Res 5: 1063-1071.

Grand EK, Chase AJ, Health C, Rahemtulla A, Cross NCP (2004) Targeting FGFR3 in multiple myeloma: inhibition of $\mathrm{t}(4 ; 14)$-positive cells by SU5402 and PD173074. Leukemia 18: 962-966.

Grose R, Fantl V, Werner S, Chioni AM, Jarosz M, Rudling R, Cross B, Hart IR, Dickson C (2007) The role of fibroblast growth factor receptor $2 \mathrm{~b}$ in skin homeostasis and cancer development. EMBO J 26: 1268-1278.

Gumbiner BM (2005) Regulation of cadherin-mediated adhesion in morphogenesis. Nat Rev Mol Cell Biol 6: 622-634.

Hong KO, Kim JH, Hong JS, Yoon HJ, Lee JI, Hong SP, Hong SD (2009) Inhibition of Akt activity induces the mesenchymal-to-epithelial reverting transition with restoring E-cadherin expression in KB and KOSCC-25B oral squamous cell carcinoma cells. J Exp Clin Cancer Res 28: 28.

Kudo Y, Kitajima S, Ogawa I, Hiraoka M, Sargolzaei S, Keikhaee MR, Sato S, Miyauchi M, Takata T (2004) Invasion and metastasis of oral cancer cells require methylation of E-cadherin and/or degradation of membranous beta-catenin. Clin Cancer Res 10: 5455-5463.

Lamont FR, Tomlinson DC, Cooper PA, Shnyder SD, Chester JD, Knowles MA (2011) Small molecule FGF receptor inhibitors block FGFR-dependent urothelial carcinoma growth in vitro and in vivo. Br J Cancer 104: 75-82.

Mao L, Hong WK, Papadimitrakopoulou VA (2004) Focus on head and neck cancer. Cancer Cell 5: 311-316.

Mohammadi M, Froum S, Hamby JM, Schroeder MC, Panek RL, Lu GH, Eliseenkova AV, Green D, Schlessinger J, Hubbard SR (1998) Crystal structure of an angiogenesis inhibitor bound to the FGF receptor tyrosine kinase domain. EMBO J 17: 5896-5904.

Moreno-Bueno G, Cubillo E, Sarrio D, Peinado H (2006) Genetic profiling of epithelial cells expressing E-cadherin repressors reveals a distinct role for 
Snail, Slug, and E47 factors in epithelial-mesenchymal transition. Cancer Res 66: 9543-9556.

Nieto MA (2002) The Snail superfamily of zinc-finger transcription factors. Nat Rev 3: 155-166.

Olmeda D, Jorda M, Peinado H, Fabra A, Cano A (2007) Snail silencing effectively suppress tumor growth and invasiveness. Oncogene 26: 1862-1874.

Prusty BK, Das BC (2005) Constitutive activation of transcription factor AP-1 in cervical cancer and suppression of human papillomavirus (HPV) transcription and AP-1 activity in HeLa cells by curcumin. Int J Cancer 113: 951-960.

Shaulian E, Karin M (2001) AP-1 in cell proliferation and survival. Oncogene 20: 2390-2400.

Stachowiak ER, Maher PA, Tucholski J, Mordechai E, Joy A, Moffett J, Coons S, Stachowiak MK (1997) Nuclear accumulation of fibroblast growth factor receptors in human glial cells-association with cell proliferation. Oncogene 14: 2201-2211.

Stachowiak MK, Fang X, Myers JM, Dunham SM, Berezney R, Maher PA, Stachowiak ER (2003) Integrative Nuclear FGFR1 signaling (INFS) as a part of an universial "Feed-Forward-And-Gate" signaling module that controls cell growth and differentiation. J Cell Biochem 90: 662-691.

Taki M, Kamata N, Yokoyama K, Fujimoto R, Tsutsumi S, Nagayama M (2003) Down-regulation of Wnt-4 and up-regulation of Wnt-5a expression by epithelial-mesenchymal transition in human squamous carcinoma cells. Cancer Sci 94: 593-597.
Turner N, Pearson A, Sharpe R, Lambros M, Geyer F, Lopez-Garcia MA, Natrajan R, Marchio C, Iorns E, Mackay A, Gillett C, Grigoriadis A, Tutt A, Reis-Filho JS, Ashworth A (2010) FGFR1 amplification drives endocrine therapy resistance and is a therapeutic target in breast cancer. Cancer Res 70: 2085-2094.

Yilmaz M, Christofori G (2011) Mechanisms of motility in metastasizing cells. Mol Cancer Res 8: 629-642.

Yokoyama K, Kamata N, Fujimoto R, Tsutsumi S, Tomonari M, Taki M, Hosokawa H, Nagayama M (2003) Increased invasion and matrix metalloproteinase- 2 expression by Snail-induced mesenchymal transition in squamous cell carcinomas. Int J Oncol 22: 891-898.

Yokoyama K, Kamata N, Hayashi E, Hoteiya T, Ueda N, Fujimoto R, Nagayama M (2001) Reverse correlation of E-cadherin and snail expression in oral squamous cell carcinoma cells in vitro. Oral Oncol 37: 65-71.

Zhou BP, Deng J, Xia W, Xu J, Li YM, Gunduz M, Hung MC (2004) Dual regulation of Snail by GSK-3ß-mediated phosphorylation in control of epithelial-mesenchymal transition. Nat Cell Biol 6: 931-940.

(c) (1) (2) This work is licensed under the Creative Commons AY NG SA Attribution-NonCommercial-Share Alike 3.0 Unported License. To view a copy of this license, visit http://creativecommons. org/licenses/by-nc-sa/3.0/ 